\title{
Periodic Breathing in Premature and Neonatal Babies: Incidence, Breathing Pattern, Respiratory Gas Tensions, Response to Ghanges in the Composition of Ambient Air
}

Axel Fenner ${ }^{[25]}$, Ulrike Sahalk, Heidi Hoenicke, Adelheid Wendenburg, and Thomas Roehling

Kinderklinik der Medizinischen Akademie, Lübeck, Germany

\section{Extract}

Periodic breathing (PB) is a respiratory pattern of young infants during the first few weeks of life and is due presumably to "immaturity" of the respiratory center. It has no pathologic significance and must thus be sharply distinguished from true apneic spells.

Measurements and tests done on 141 infants exhibiting periodic breathing showed the following results. (1) The incidence of $\mathrm{PB}$ is $36.1 \%$ in infants weighing more than $2,500 \mathrm{~g}$ at birth, and $94.5 \%$ in infants of low birth weight. (2) Periodic breathing begins after the first 1-2 days of life; it may persist for several weeks depending on the degree of the baby's prematurity. (3) Mean duration of apneic periods was $6.9 \mathrm{sec}$; mean number of apneic periods per minute varied from 5 to less than 1. (4) Endtidal $\mathrm{P}_{\mathrm{CO}_{2}}$ showed a mean figure of $29.15 \mathrm{~mm} \mathrm{Hg}$ during regular breathing; after the end of an apneic period it was $32.36 \mathrm{~mm} \mathrm{Hg}$. Corresponding values for end-tidal $\mathrm{O}_{2}$ were 113.58 and $98.33 \mathrm{~mm} \mathrm{Hg}$, respectively. (5) Ambient $\mathrm{CO}_{2}$ in air tended to cause a gradual decrease in the number of apneic episodes as $\mathrm{CO}_{2}$ was raised. At $3.15 \%$ $\mathrm{CO}_{2}, \mathrm{~PB}$ had practically disappeared in all patients. The $\mathrm{CO}_{2}$ did not have an effect on the duration of individual apneic episodes, as long as such were present. (6) Ambient $\mathrm{O}_{2}$ had no effect on either duration or frequency of apneic episodes up to a certain characteristic level. If that particular $\mathrm{O}_{2}$ concentration in the environment of the baby was reached, PB abruptly turned to a regular breathing pattern ("turning point"). The "turning point" was a characteristic, and on any given day, reproducible finding in any given infant exhibiting PB. It would go down with time with a slope very similar for all infants, although absolute values varied considerably between different individuals.

\section{Speculation}

Periodic breathing is a respiratory pattern of healthy young infants. The regulatory mechanisms causing $\mathrm{PB}$ are quite different from the respiratory control mechanisms known to exist in older individuals. In some respects, they may even appear paradoxical. 


\section{Introduction}

Periodic breathing is a respiratory pattern observed primarily in premature infants. Avery [2], in an attempt to define $\mathrm{PB}$ and to delineate it from other breathing patterns of young infants (e.g., "apneic spells"), listed the following criteria. (1) PB occurs primarily in well premature infants of more than $24 \mathrm{hr}$ of age. (2) Periods of apnea last 5-10 sec; periods of regular breathing last $10-15 \mathrm{sec}$. (3) Mean respiratory frequency is $30-40 / \mathrm{min}$; during periods of regular breathing frequency is $50-60 / \mathrm{min}$. (4) No cyanosis and no change in heart rate are observed in PB. (5) The blood of infants exhibiting $\mathrm{PB}$ is slightly alkalotic (mean pH 7.44). (6) PB is more common and tends to last longer in very small premature infants in whom it may persist for 6 weeks. It is rarely seen in infants weighing more than $2 \mathrm{~kg}$ and/or of a gestational age of more than 36 weeks.

According to the above definition, PB must be considered a nonpathologic condition of the immature. It has to be sharply differentiated from true spells of apnea some of which are known to be convulsive equivalents [15].

From the systematic observations and investigations reported in the literature, the following conclusions can be drawn in addition to Avery's criteria. (1) PB occurs in $30-45 \%$ of premature infants $[4 ; 13]$. (2) High ambient oxygen may cause disappearance of $\mathrm{PB}$ [18]. (3) Ambient $\mathrm{CO}_{2}$ causes disappearance of $\mathrm{PB}$ [6; $18]$.

This paper represents the result of a comprehensive study aimed at the elucidation of the physiologic mechanisms underlying the occurrence of $\mathrm{PB}$ done over a 4-year period. In detail, the following areas will be discussed: ( 1 ) incidence of PB; (2) measurements of respiratory gas tensions in infants exhibiting $\mathrm{PB}$; (3) response of $\mathrm{PB}$ to ambient $\mathrm{CO}_{2} ;(4)$ response of $\mathrm{PB}$ to ambient $\mathrm{O}_{2}$.

\section{Materials and Methods}

A total of 141 patients in our newborn ward were tested. All patients of less than $48 \mathrm{hr}$ of age who are referred from maternity hospitals are admitted to the ward. Since this is the only newborn referral center within a rural areal of about $40 \mathrm{~km}$, there is a mixed population of true premature infants and neonates with other disorders.

The study was conducted over the course of several years; the different steps were carried out in different groups of patients.

\section{Assessment of Incidence}

To calculate the incidence of periodic breathing $(\mathrm{PB})$ in such a mixed newborn population, 91 patients admitted consecutively were observed carefully every other day for a period varying from 2 to 11 weeks, depending on the duration of their respective hospital stays. Examination consisted in careful observation of the respiratory pattern for at least $5 \mathrm{~min}$ when the patient was presumably in rapid eye movement (REM) sleep [15]. When there was any doubt as to whether $\mathrm{PB}$ was no longer observed in a patient who had previously shown such, a recording of the respiratory pattern was performed using an impedance pneumograph [19] for objective assessment.

\section{Registration of Different Parameters}

To estimate some physiologic parameters associated with $\mathrm{PB}$, registration of respiration and respiratory gases was performed in 20 patients: for respiratory frequency and incidence and duration of $\mathrm{PB}$, impedance pneumography was performed. End-tidal $\mathrm{CO}_{2}$ and $\mathrm{O}_{2}$ determinations were done continuously by analyzing respiratory gas sampled from the nose via a small plastic catheter at a flow of 80 liters $/ \mathrm{hr}$. For $\mathrm{CO}_{2}$ analysis, an instantaneous $\mathrm{CO}_{2}$ analyzer [20] was used. The $\mathrm{O}_{2}$ was determined similarly using a rapidly responding polarographic $\mathrm{O}_{2}$ electrode (response time $0.20-0.25 \mathrm{sec}$ for $95 \%$ deflection) which was placed immediately beyond the $\mathrm{CO}_{2}$ analyzing chamber [3] In addition, the electrocardiogram was continuously monitored. All signals were displayed on the oscillographic screen of a recorder [21] and recorded on paper.

\section{$\mathrm{CO}_{2}$ Administration}

In 10 patients with spontaneous $\mathrm{PB}$ in room air, the effect of inspiratory $\mathrm{CO}_{2}$ was tested. A small plastic box [22] was placed over the baby's head. Since buildup of expired $\mathrm{CO}_{2}$ within the box was desired, a very small flow of $\mathrm{O}_{2}$ was led into the box. This was just enough to counterbalance $\mathrm{O}_{2}$ consumption in order to prevent a drop of environmental $\mathrm{O}_{2}$ concentration below $21 \%$. To achieve such accurate adjustment, a certain amount of skill was necessary initially, but with experience, adjustment proved to be quite successful. Tests were disregarded for calculation when $\mathrm{O}_{2}$ concentration was less than $20 \%$ or more than $23 \%$.

The mean number of apneic periods per unit of time as well as the mean duration of apneic periods were recorded using an impedance pneumograph [19] 


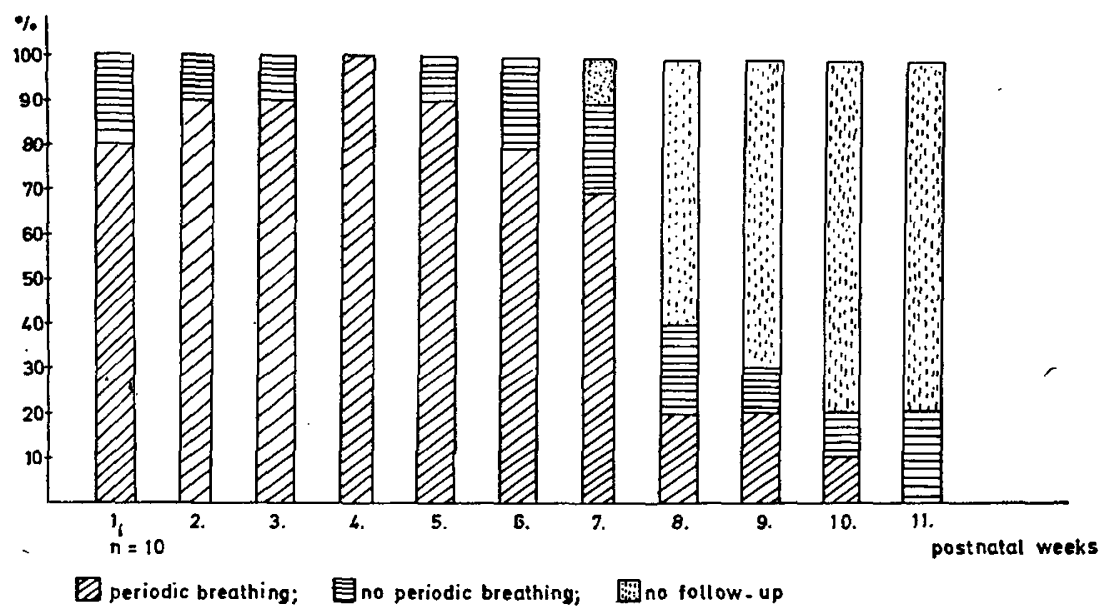

Fig. 1. Respiratory observations in 10 very small premature infants (birth weight $1,000-1,500 \mathrm{~g}$ ) during the first few weeks of life. Respiration was checked every other day. Note: periodic breathing is present in most of the subjects up to the 6th week of life. During the 4 th week, all 10 infants were breathing periodically. From the 7th week on, an increasing number of subjects are lost to follow-up because of discharge from the hospital. In the remaining two infants observed at 11 weeks of age, periodic breathing had disappeared. For statistical analysis, results were pooled. The incidence of PB during week 1 through waek 6 was significantly increased when compared with weeks 7 through $11(P<0.01)$.

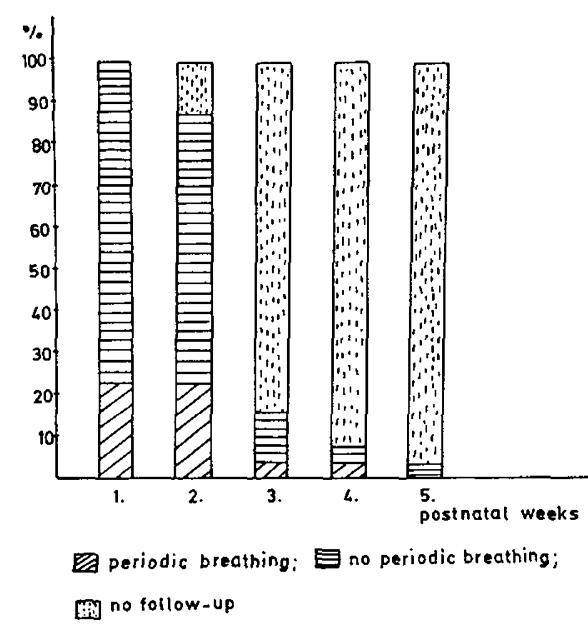

Fig. 2. Results of respiratory observations in 25 mature newborn infants (birthweight $>3,000 \mathrm{~g}$ ) during the first few weeks of life. Respiration was checked every other day. Note: during week 1, the occurrence of $\mathrm{PB}$ in this group of infants was $25 \%$. The subsequent disappearance rate could not be fully estimated, inasmuch as many of these infants were rapidly lost to follow-up because of discharge from the hospital.

at four levels of inspired $\mathrm{CO}_{2}: 0 \%=0 \mathrm{~mm} \mathrm{Hg}$ (prior to the experiment), $0.75 \%=5.3 \mathrm{~mm} \mathrm{Hg}, 1.55 \%=11.0$ $\mathrm{mm} \mathrm{Hg}, 3.10 \%=22.0 \mathrm{~mm} \mathrm{Hg}$. After this testing procedure, another "zero period" was run. The $\mathrm{CO}_{2}$ monitoring was continuous; the suction tube of the infrared $\mathrm{CO}_{2}$ analyzer [20] was left in place within the plastic box close to the baby's face. The $\mathrm{O}_{2}$ monitoring was done intermittently several times each minute using an oxygen analyzer [23]. Ill effects other than hyperventilation were not observed.

\section{$\mathrm{O}_{2}$ Administration}

In 30 additional patients exhibiting spontaneous $\mathrm{PB}$ while breathing room air, $\mathrm{O}_{2}$ was gradually raised by again placing the plastic hood over the head and leading pure oxygen (not preheated and unmoisturized) into it through its inlet hole. The fit was not tight around the neck; thus, $\mathrm{CO}_{2}$ accumulation as well as pressure build-up were prevented. Oxygen flow was kept high enough to ensure complete washout of $\mathrm{CO}_{2}$, and low enough to prevent development of noticeable turbulence around the baby's head.

Oxygen was frequently monitored using an oxygen analyzer [23]. When periodic breathing was observed to disappear, inspired oxygen was carefully lowered until PB reappeared. The procedure was repeated, thus making possible the determination of an exact concentration of oxygen at which PB turned into regular breathing. This concentration was then called "turning point."

The total procedure required approximately 30 min. Signs of oxygen toxicity were not observed and careful ophthalmologic examination was carried out in each patient before discharge from the hospital.

When we found that the "turning point" went down in any given individual on subsequent testing, the procedure was repeated about once a week until PB had disappeared in room air, except in those patients who 


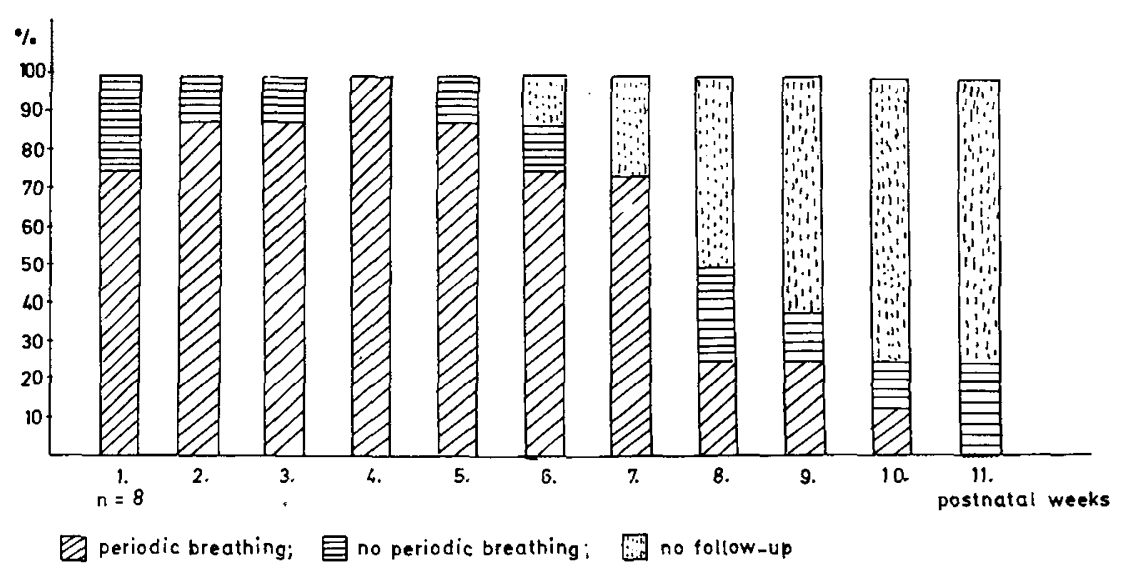

Fig. 3. Results of respiratory observations in eight very immature infants during the first few weeks of life (gestational age 29-31 weeks). Respiration was checked every other day. Note: periodic breathing was present in most of the subjects up to the 5th week of life. During the 4th week, all eight infants were breathing periodically. From the 6 th week on, an increasing number of patients were lost to follow-up due to discharge from the hospital. It appears however, that the incidence of PB decreases rapidly after the 7th week of life.

were discharged from the hospital prior to the disappearance of PB. Thus, all 30 subjects were tested on at least two and up to five occasions.

\section{Statistical Analysis}

For statistical evaluation of the data, following standard methods were applied: ( $l$ ) calculation of mean values $\pm \mathrm{sD}$; (2) Student $t$ test for calculation of significant differences in comparing mean results of two different populations; (3) standard formula for calculation of linear regressions of paired values.

\section{Results}

\section{Incidence}

Of 91 consecutively admitted premature and newborn infants, a total of $66(72.5 \%)$ exhibited PB at some time during their hospital stay.

In premature infants the incidence was much higher than in full-term newborns: in 52 babies of a gestational age of less than 37 weeks the total rate was $86.5 \%$ (= 45 infants) as compared with $41.03 \%$ (16 out of 39 infants) in mature neonates (Fig. 4). When division is done by birth weight, the incidence in the low birth weight group $(<2,500 \mathrm{~g})$ was $94.5 \%$ in comparison with $36.1 \%$ ( 13 out of 36 ) among infants of normal birth weight.

Figures 1-4 illustrate the incidence and course of $\mathrm{PB}$ in four representative groups of patients. $\mathrm{PB}$ tends to occur more frequently and to persist longer in the more immature individuals. Unfortunately, follow-up was difficult, particularly in the larger babies, since they were usually discharged from the hospital before

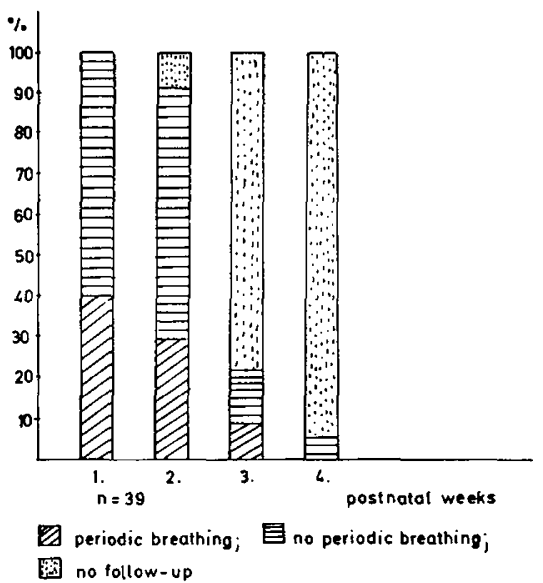

Fig. 4. Results of respiratory observations in 39 full term newborns during the first few weeks of life (gestational age $>37$ weeks). Respixation was checked every other day. Note: periodic breathing was present in $40 \%$ of these subjects during the first week of life. The subsequent disappearance rate was difficult to assess because of loss of follow-up after discharge from the hospital.

their PB had disappeared. Figures 5 and 6 show the relative incidence of $\mathrm{PB}$ as it relates to actual body weight (Fig. 5) and postconceptional age (Fig. 6), respectively. The results may be somewhat misleading in that they are not based on a fixed number of infants because loss to follow-up as mentioned above. Rather, they give incidence of $\mathrm{PB}$ in percentage of total observations. However, the tendency of a linear decline with time is most impressive. The time course of PB is fairly uniform in most infants; rarely is PB observed in the first 2 days of life. Peak incidence is seen during the 2nd and 3rd week; subsequent disappearance rate 


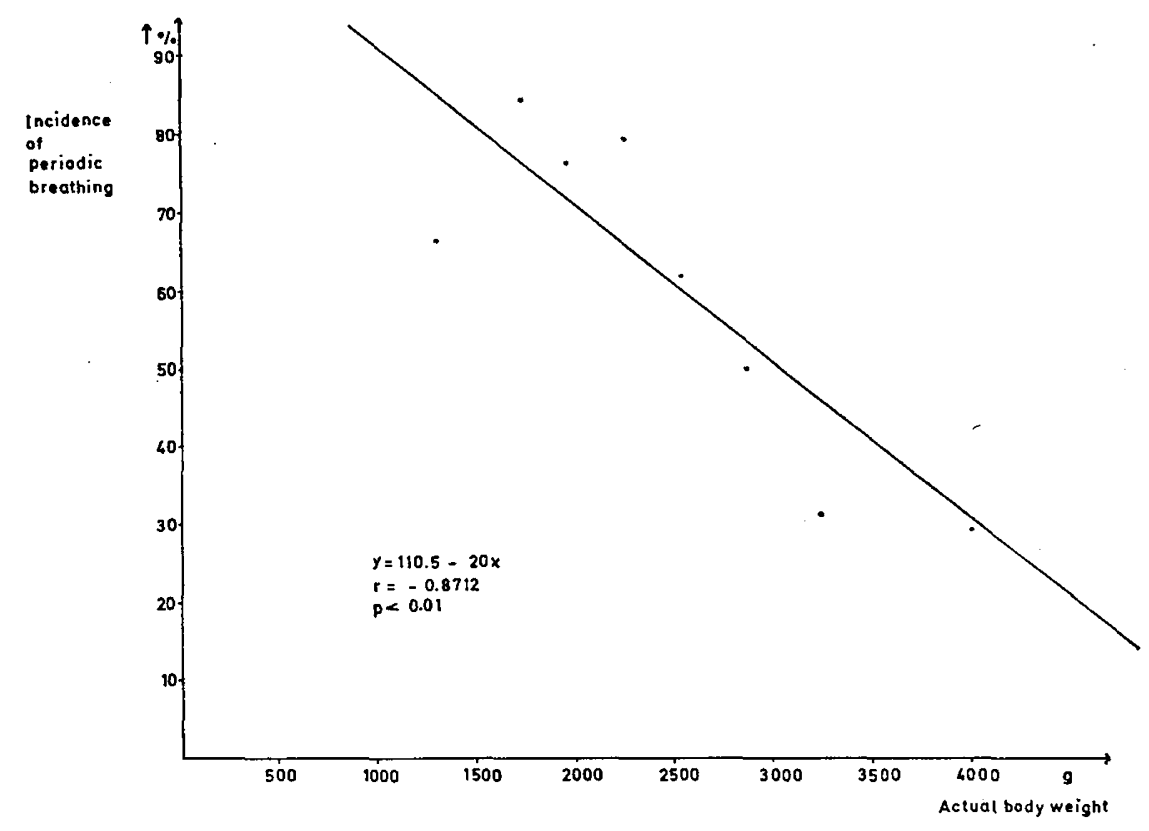

Fig. 5. Correlation of frequency of apneic periods to actual body weight. The ordinate represents the percentage of positive (i.e., infants with apneic periods) observations with respect to the total number of observations. It does not relate to a given number of infants observed.

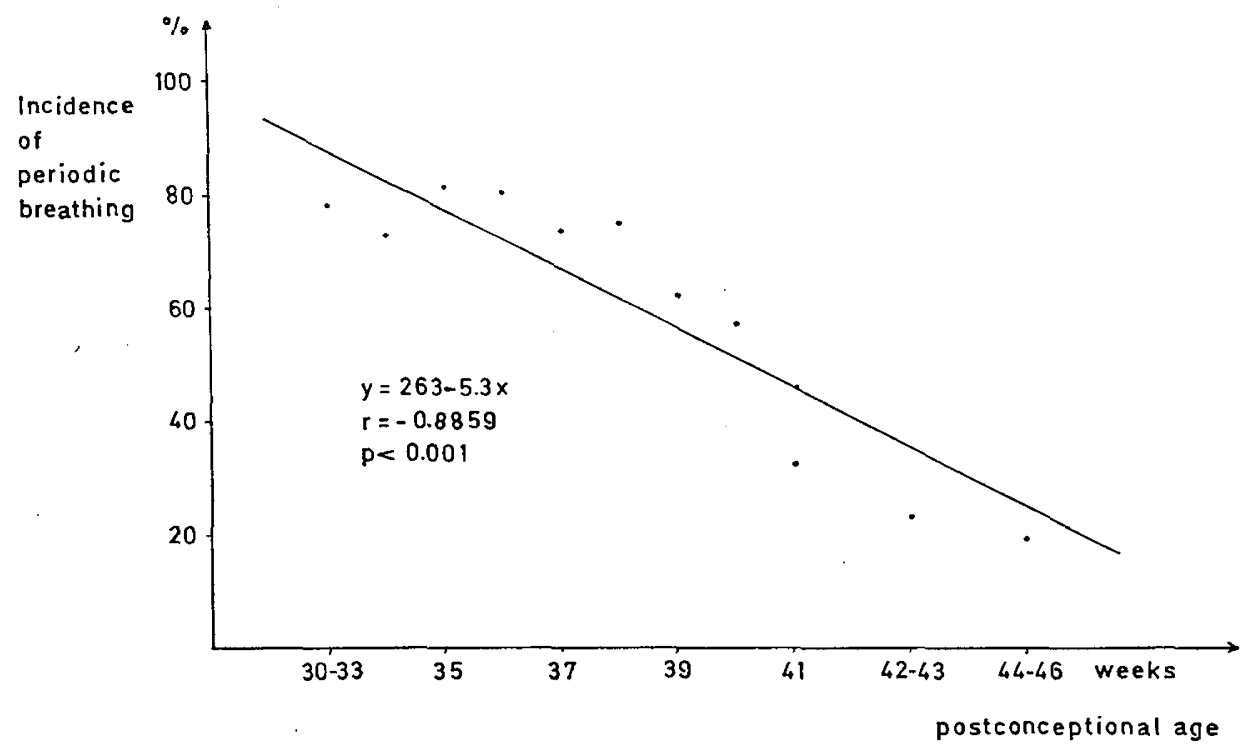

Fig. 6. Plot similar to that in Figure 5: correlation of "incidence" of periodic breathing to postconceptional age (= gestational age at birth + postnatal age). The ordinate gives percentage of observations of $\mathrm{PB}$ rather than being related to a given number of subjects.

depends largely on initial maturity; the more premature, the longer is PB likely to persist.

\section{Assessment of Different Parameters Associated with Periodic Breathing}

Frequency of apneic periods varies from one individual to another and also, within the same baby. This is probably related to the state of vigilance; most fre- quently, $\mathrm{PB}$ occurs while the baby is in REM sleep. In 20 patients in whom we studied 188 apneic periods, mean frequency was $6.3 \pm 2.9 / 3$-min period, mean duration of single apneic periods $6.88 \pm 0.56 \mathrm{sec}$ (range 3-12 sec). Mean respiratory frequency in the series was $43.2 \pm 10.74$ breaths/min [10].

Figure 7 shows a typical recording obtained from an infant exhibiting PB. No change in heart rate occurred 
during the apneic period. This finding was so constant that we consider it one of the most reliable criteria of $\mathrm{PB}$ as opposed to true apneic spells. Likewise, cyanosis was never observed in periodically breathing infants.

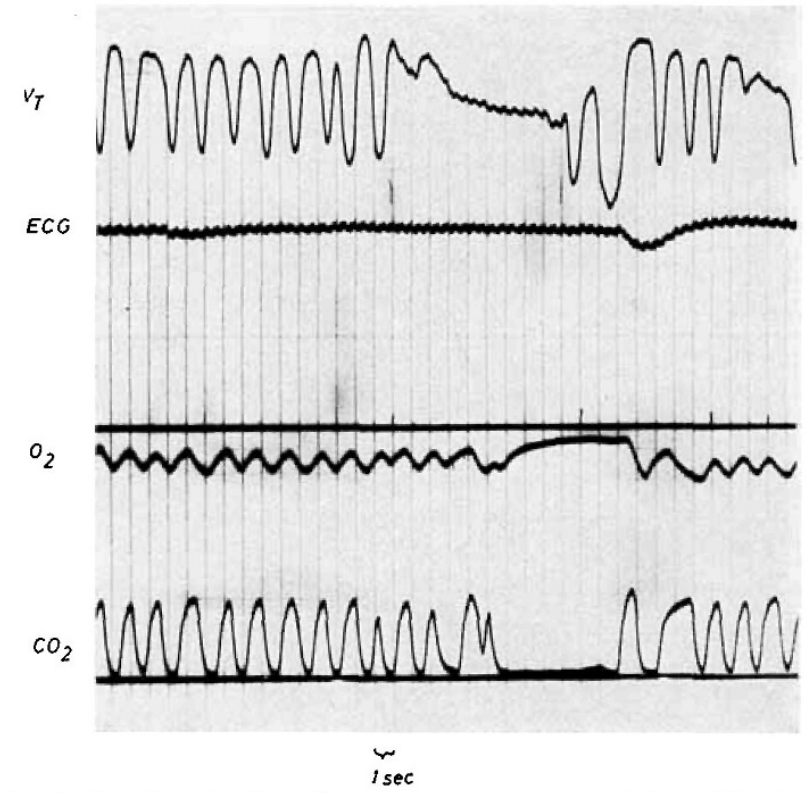

Fig. 7. $V_{r}$ : Respiration (impedance pneumography); ECG: electrocardiography; $\mathrm{O}_{2}: \mathrm{O}_{2}$ in respired air/inspiration-upward strokes (polarographic); $\mathrm{CO}_{2}: \mathrm{CO}_{2}$ in respired air/inspiration-upward strokes (ultrared $\mathrm{CO}_{2}$ analyzer). Note: after regular breathing, an apneic episode of $9 \mathrm{sec}$ occurred during which the respiratory record showed only the small "wiggles" of superimposed heartbeats. Cardiac frequency remained unchanged throughout the apneic period. The $\mathrm{O}_{2}$ and $\mathrm{CO}_{2}$ showed an increased amplitude immediately after reappearance of respiration.
End-tidal $\mathrm{P}_{\mathrm{CO}_{2}}$ values varied considerably, depending to a great extent on the duration of the apneic periods. Mean values were: $29.15 \pm 1.94 \mathrm{~mm} \mathrm{Hg}$ during breathing periods, $32.36 \pm 2.22 \mathrm{~mm} \mathrm{Hg}$ following nonbreathing periods. The mean difference thus is $3.22 \mathrm{~mm} \mathrm{Hg}$ [10]. Comparison of individual differences by means of the $t$ test for paired values, shows a high statistical significance $(P<0.001)$.

End-tidal $\mathrm{P}_{\mathrm{O}_{2}}$ showed a mean value of $113.58 \pm 7.37$ $\mathrm{mm} \mathrm{Hg}$ during regular breathing, $98.33 \pm 10.42 \mathrm{~mm}$ $\mathrm{Hg}$ after apneic periods. The mean difference of $\mathbf{1 5 . 2 5}$ $\mathrm{mm} \mathrm{Hg}$ is also highly significant when calculation is performed according to the $t$ test for paired values $(P<0.005)$.

\section{$\mathrm{CO}_{2}$ Administration}

With increasing $\mathrm{CO}_{2}$ concentration in ambient air, PB could be abolished. The critical concentration necessary to make $\mathrm{PB}$ turn into regular breathing, was between 2 and $4 \% \mathrm{CO}_{2}$ in air. Interestingly, the duration of apneic periods did not change significantly, before PB disappeared completely (Fig. 8). On the other hand, there was a gradual decrease in the number of apneic periods as $\mathrm{CO}_{2}$ was gradually increased (Fig. 9).

\section{$\Theta_{2}$ Administration}

The most surprising effect was noticed when $\mathrm{O}_{2}$ was raised in ambient air. As with $\mathrm{CO}_{2}$ application, $\mathrm{PB}$ could also be made to disappear when $\mathrm{O}_{2}$ was administered. Figure 10 demonstrates a recording of a test

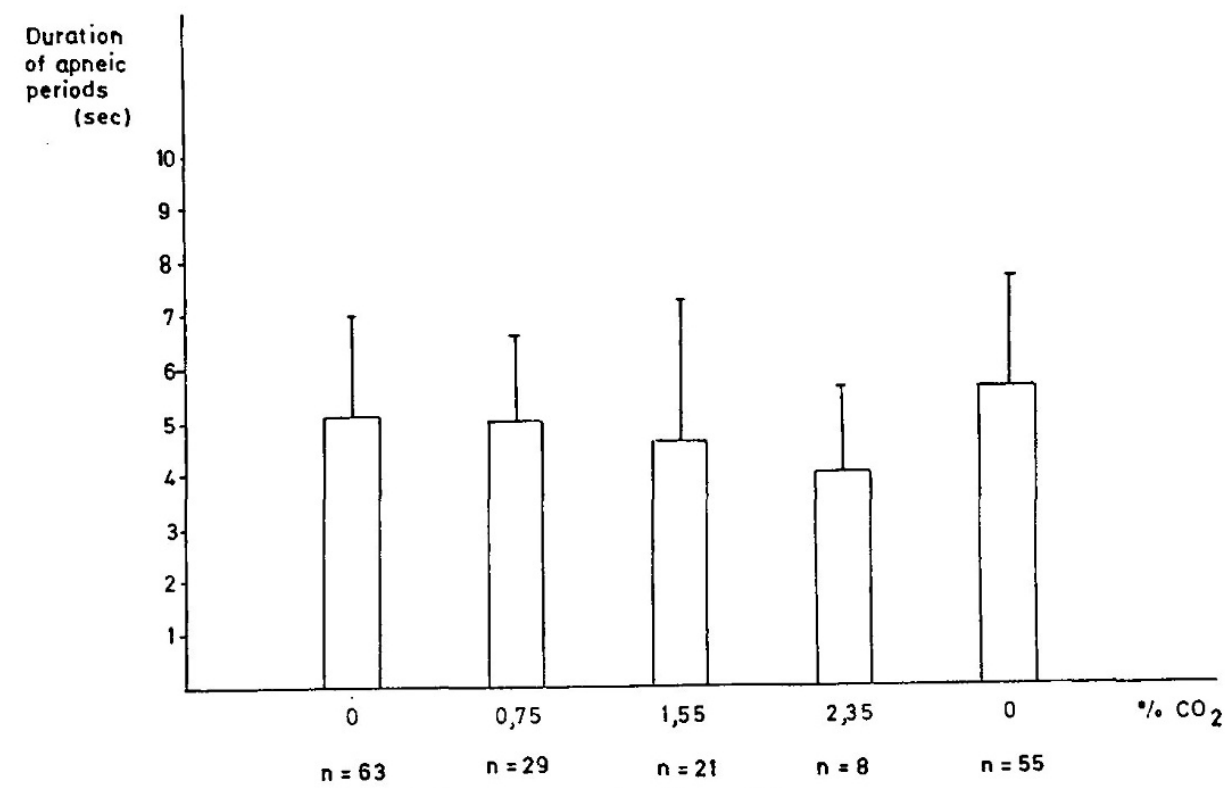

Fig. 8. Mean duration +1 SD of apneic periods at different levels of ambient $\mathrm{CO}_{2}$. 


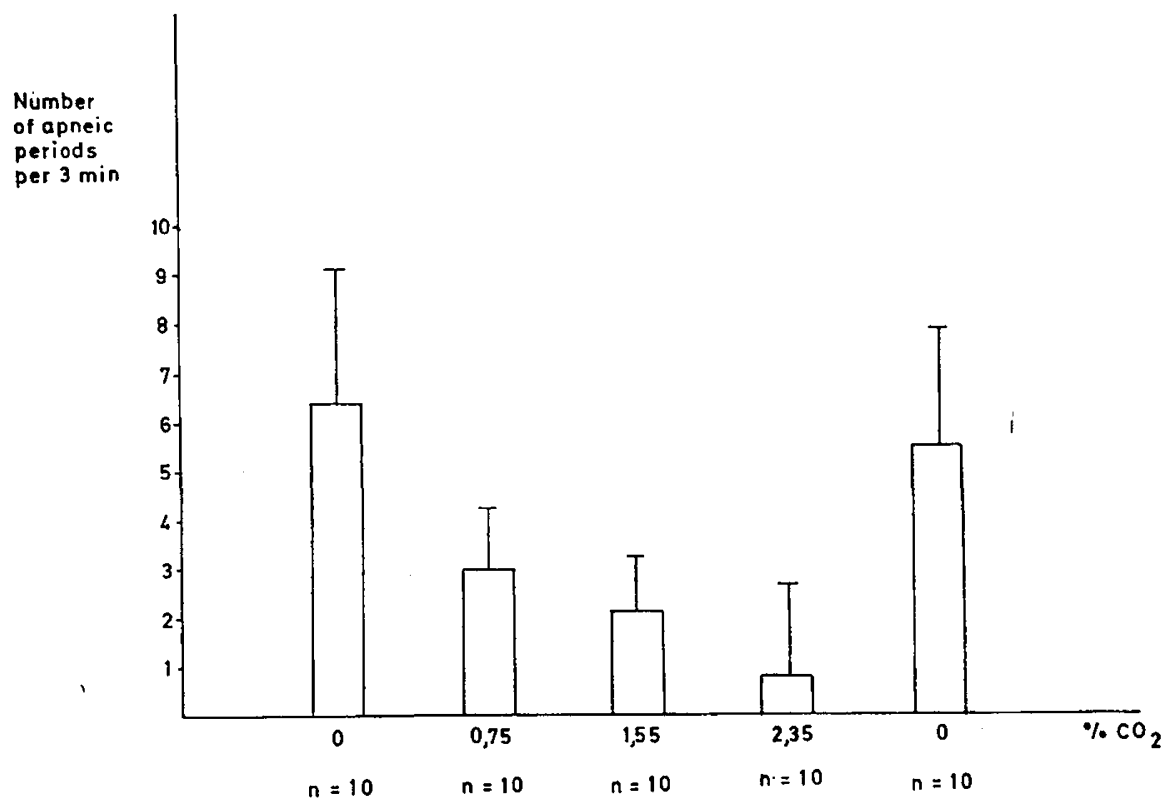

Fig. 9. Mean number $+1 \mathrm{sD}$ of apneic periods at different levels of ambient $\mathrm{CO}_{2}$. Note: the number of apneic periods decreased steadily as the $\mathrm{CO}_{2}$ concentration was raised. The last bar represents the control value after termination of the test period. Levels of statistical significance:

$$
\begin{aligned}
0 \% \text { (initial) } & \leftrightarrow 0.75 \% P<0.0025 \\
0.75 \% & \leftrightarrow 1.55 \% 0.20>P>0.10 \\
1.55 \% & \leftrightarrow 2.35 \% P<0.025 \\
0.75 \% & \leftrightarrow 2.35 \% P<0.0025 \\
0 \% \text { (initial) } & \leftrightarrow 0 \% \text { (terminal) } 0.30>P>0.25
\end{aligned}
$$

done in a premature infant on one particular day: a critical threshold level of $\mathrm{O}_{2}$ was reached at $46 \%$. At this point $\mathrm{PB}$ abruptly changed to regular respiration [11]. When we attempted to study this phenomenon longitudinally, a decrease in the threshold concentration ("turning point") was found on subsequent testing several days later (Fig. 11). In 30 infants followed between two and five times in this manner, a striking similarity could be demonstrated in the slope at which the "turning point" went down during their early postnatal development (Figs. 12 and 13). This was all the more surprising, since the initial level of the "turning point" was not at all similar in infants comparable with respect to size (body weight, Fig. 12) and/or development (postconceptional age, Fig. 13).

Unlike the $\mathrm{CO}_{2}$ response, $\mathrm{O}_{2}$ caused no change in either duration or number of apneic periods until the threshold concentration ("turning point") was actually reached [12].

\section{Discussion}

The incidence of $\mathbf{P B}$ as given in this paper has been the highest thus far reported. This is particularly true for premature babies. Other groups have given figures of $75.7 \%$ [18], $56 \%$ [3], and $44 \%$ [13], respectively. Chernick et al. [5] pointed out that PB may occur predominantly during periods of "active sleep." We are convinced that this may be the reason that our own incidence is so high; we always observed the infants at a time shortly after the meal when they were presumably in REM sleep [15].

Our incidence for full term neonates is close to that reported by others: $40.5 \%$ [8], $40 \%$ [14], as compared with $41.03 \%$ in our own series. Differences in the definition of maturity may account for the small discrepancy. On the basis of our own findings and the survey of the literature, we are hesitant to agree with Chernick et al. [5], Avery [2], or Dietel [9], who consider $\mathrm{PB}$ a respiratory pattern that is practically nonexistent in full term infants.

One further point to be considered when discrepant results are obtained, is the interesting phenomenon observed by Daily et al. [7] of a dependency of "apnea" on environmental temperature. In our series, all observations were made in a constant thermal environment $\left(22^{\circ}\right)$ with the exception of the very young and very low weight infants, who were still in the incubator. 
The mean duration of apneic periods is in agreement with that reported by Chernick et al. [5]. This and the lack of change in heart rate facilitates the distinction of periodic breathing from true apneic spells. Clinically there is an important difference, in that PB must be considered a benign, "physiologic" breathing pattern of young infants, whereas apneic spells are usually a pathologic symptom of some neurologic disturbance, frequently seizures [15].

Our respiratory $\mathrm{CO}_{2}$ measurements are in agreement with those of Chernick et al. [5]. We do agree with their statement that $\mathrm{PB}$ is a pattern of slight hyperventilation. The build-up of $\mathrm{CO}_{2}$ during apneic periods showed a lower mean figure in our group of subjects. To our knowledge, no results have been published on respiratory $\mathrm{O}_{2}$ measurements. Our figures confirm the fact that the infants are hyperventilating. The relatively greater difference between pre- and postapnea end-tidal $\mathrm{O}_{2}$ tension values is noteworthy. It is in keeping with the notion of Avery [2], who commented on the difference in incidence of $\mathrm{PB}$ among full term infants between cities of different barometric pressure. We may add that lübeck, the city where our own experiments were conducted, is at sea level.

The response to $\mathrm{CO}_{2}$ in our series is similar to that found by other investigators $[6,16,18]$. The PB can be made to disappear; the concentration of $\mathrm{CO}_{2}$ necessary is $2-4 \%$. The mechanism is most likely a mere hyperventilation due to $\mathrm{CO}_{2}$.

Without question the most interesting aspect is the response of $\mathrm{PB}$ to $\mathrm{O}_{2}$. From studies on Cheyne-Stokes breathing in adults, Anthony et al. [1] were able to demonstrate a change in the periodic respiratory pattern upon administration of $80 \% \mathrm{O}_{2}$, although the periodicity did not regularly disappear. Another well known phenomenon is the occurrence of a periodic type of respiration at high altitude which is convertible when oxygen is administered [1]. Whether or not these conditions are, in any respect, analogous to what we call "periodic breathing of infancy," remains open to question.

Wilson et al. [18] were the first workers to point out that PB of young infants can also be influenced by high ambient oxygen, in that $\mathrm{PB}$ is converted into a regular breathing pattern. On the basis of Wilson's findings, our own investigation was aimed at the quantification of this phenomenon. As a result, a "turning point" could be determined in each infant on any given day. The similarity in the slopes of decrease of the turning point in time among different individuals makes us believe that a developmental principle common to all

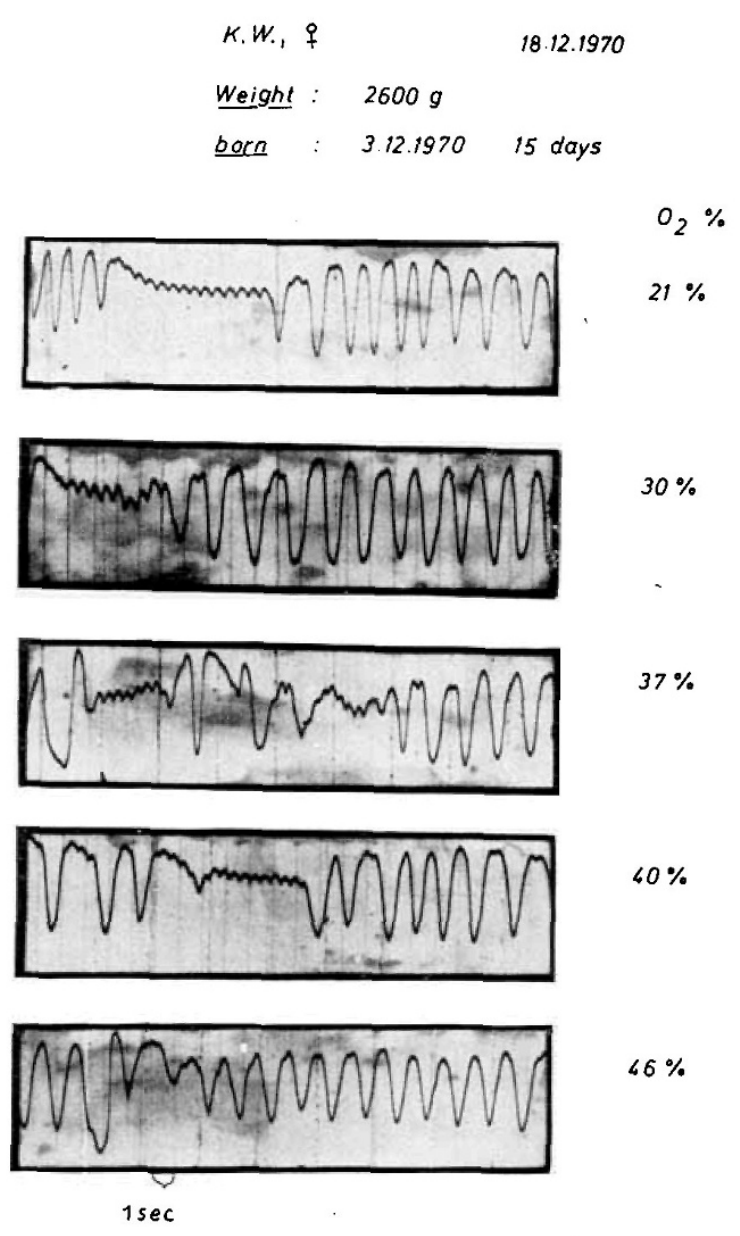

Fig. 10. Effect of a stepwise increase in $\mathrm{O}_{2}$ in inspired air on the respiratory pattern of a young premature infant who exhibited spontaneous periodic breathing. Recording of respiration by impedance pneumography. Note: no effect occurred until a certain level of ambient $\mathrm{O}_{2}$ (46\% in this particular case) had been reached. This concentration of $\mathrm{O}_{2}$ necessary to convert $\mathrm{PB}$ into regular breathing has been termed "turning point" by us. It was always reproducible for any given day at an accuracy of $\pm 5 \%$.

premature babies may be operative here. The differences in the absolute $\mathrm{F}_{\mathrm{IO}_{2}}$ (fraction of $\mathrm{O}_{2}$ in inspiratory gas) values between different individuals are not fully understood at this point. The degree of right-to-left shunting may account for part of it, particularly when observations were begun during the 1st week of life [2].

The applicability of the well known laws of the respiratory control mechanisms to premature and newborn infants has been demonstrated with respect to various parameters $[2,4-6,13,17]$. However, spontaneous periodic breathing at sea level does not occur as a physiologic respiratory pattern in human individuals other than young infants. We therefore tend 


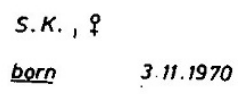

Birth weight $2000 \mathrm{~g}$
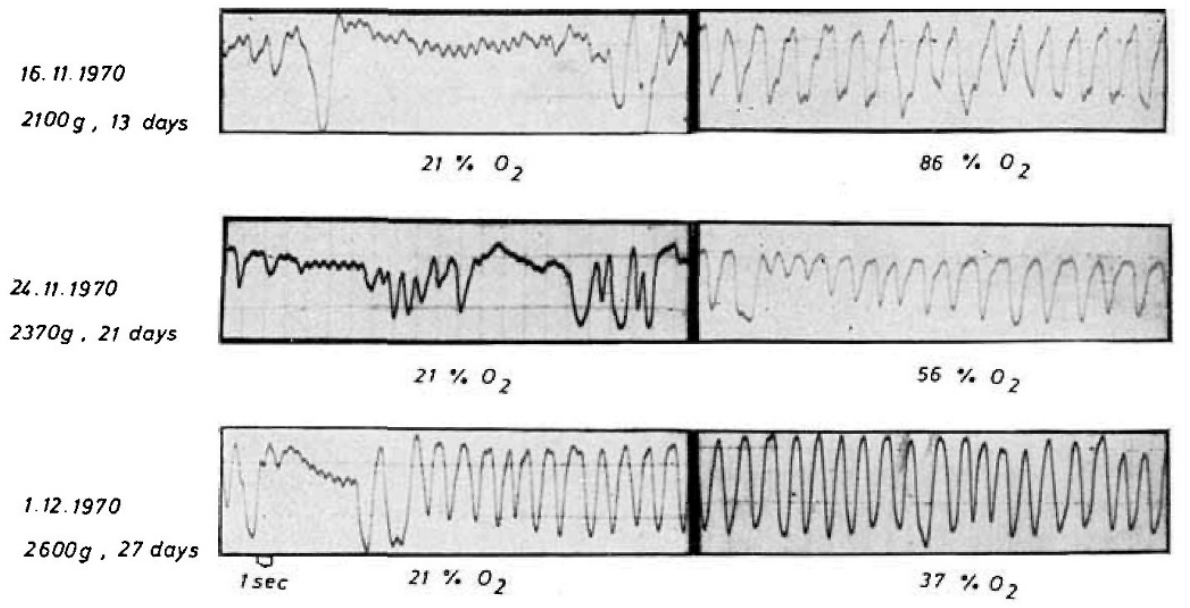

Fig. 11. Recording of the respiratory pattern (impedance pneumography) of the same patient on three different occasions. While breathing air (left panel), PB was observed each time. Stepwise increase of $\mathrm{O}_{2}$ in inspired air showed the "turning point" (see legend of Fig. 10) to be at a different $\mathrm{O}_{2}$ concentration on each occasion. Note: as the infant matured, the $\mathrm{O}_{2}$ concentration necessary for conversion of PB into regular breathing ("turning point") decreased steadily.

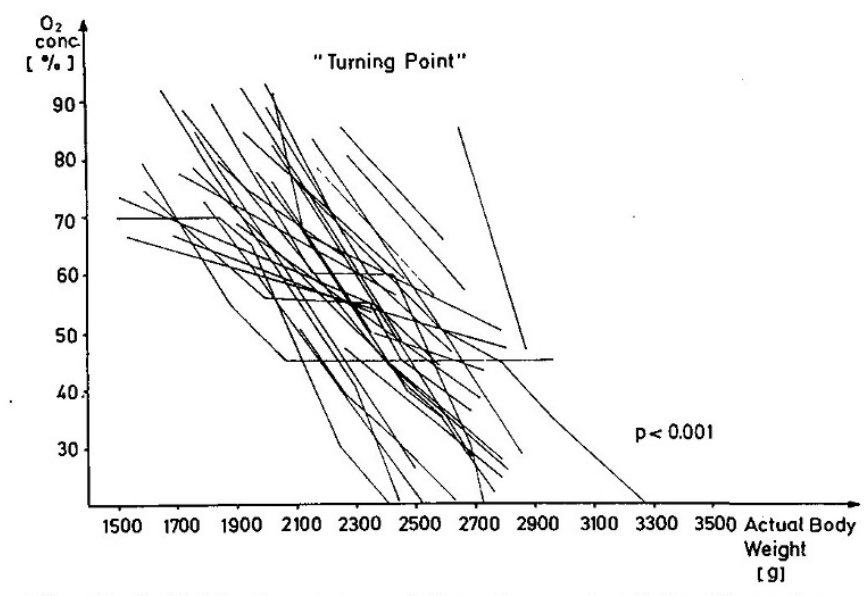

Fig. 12. Individual courses of "turning points" in 30 patients, plotted as a function of body weight. Each line was derived from two (minimum) to five (maximum) tests. Note: although the absolute level of individual "turning points" is quite variable, the slopes of decrease are surprisingly similar, which suggests a developmental pattern of postnatal respiratory "maturity" common to all infants.

to believe that more evidence is needed before we explain its origin by analogy to Cheyne-Stokes breathing of adults. Thus the response of $\mathrm{PB}$ to high ambient $\mathrm{O}_{2}$ in young infants and its time course is presented as a highly interesting phenomenon of development rather than a fully understood physiologic mechanism.
Nevertheless, one vague speculation may be allotted at the conclusion of this chapter; if the cerebral vessels are very reactive to blood gas tensions at this age, they may constrict vigorously when $\mathrm{P}_{\mathrm{O}_{2}}$ in arterial blood is high. This could render cerebral tissue slightly acidotic. The tissue acidoses would be extended to the cerebrospinal fluid and exhibit a stimulatory effect on the central chemoreceptors. The only support we can

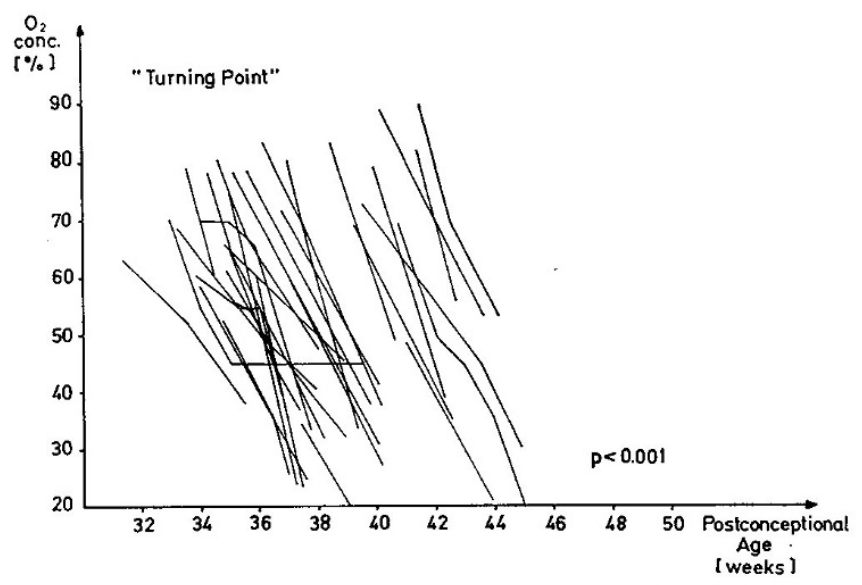

Fig. 13. Same individual regressions as in Fig. 12, plotted as a function of postconceptional age (gestational age at birth + postnatal age). The similarity in the slopes of most of the 30 infants is even more striking than in Fig. 12. 
offer to attest to the high reactivity of cerebral vessels to blood gas tensions at this age is the well known reactivity of the retinal vessels to $\mathrm{O}_{2}$ which clinically may result in retrolental fibroplasia.

\section{Summary}

Observations, measurements of physiologic parameters (respiration, heart rate, respiratory gas tensions), and response testing upon application of $\mathrm{O}_{2}$ vs $\mathrm{CO}_{2}$ were performed in a total of 141 premature and full term newborns exhibiting periodic breathing over a period of several years. The results may be summarized as follows: (1) Periodic breathing (PB) is a "physiologic" respiratory pattern of a certain percentage of young infants, the incidence being greater, the more immature the subjects. (2) Alveolar gases reveal PB to be a type of hyperventilation. (3) The $\mathrm{CO}_{2}$ in ambient air causes apneic periods to disappear, presumably by the induction of more hyperventilation. (4) The $\mathrm{O}_{2}$ in ambient air also converts $\mathrm{PB}$ to regular breathing, presumably, not by directly inducing hyperventilation.

It is speculated that high arterial $\mathrm{P}_{\mathrm{O}_{2}}$ may cause severe cerebral vascular constriction and thus, provoke central nervous system acidosis. This, in turn, could stimulate the central chemoreceptors by way of the cerebrospinal fluid.

\section{References and Notes}

1. Anthony, A. J., Cohn, A. E., And Steele, J. M.: Studies on Cheyne-Stokes respiration. J. Clin. Invest., 11: 1321 (1932).

2. Avery, M. E.: The lung and its disorders in the newborn infant. Major Problems in Clinical Pediatrics, Vol. 1, Ed. 2. (Saunders Company, Philadelphia, 1968).

3. Beneken Kolmer, H. H., And Kreuzer, F.: Continuous polarographic recording of oxygen pressure in respiratory air. Respir. Physiol., 4: 109 (1968).

4. Bouterline-Young, H. J., And Smith, C. A.: Respiration of full-term and premature infants. Amer. J. Dis. Childhood, 80: 753, (1950).

5. Chernick, V., Heldrich, F., and Avery, M. E.: Periodic breathing of premature infants. J. Pediat., 64: 330 (1964).

6. Cross, K. W., Hooper, J. M. D., ANd Oppê, T. E.: The effect of inhalation of $\mathrm{CO}_{2}$ in air on the respiration of the fullterm and premature infant. J. Physiol., 122: 264 (1953).

7. Daily, W. J. R., Klaus, M., and Meyer, H. B. P.: Apnea in premature infants: monitoring, incidence, heart rate changes, and an effect of environmental temperature. Pediatrics, 43: $510(1969)$.

8. Deming, J., And Washburn, A. H.: Respiration in infancy. $Y$. A method of studying rates, volume and character of respiration with preliminary report of results. Amer. J. Dis. Childhood, 49: 108 (1935).

9. Dietel, V.: Die Reifung des Atemzentrums bei Frühgeborenen. Z. Kinderheilk., 73: 463 (1953).

10. FENNER, A., AND SCHALK, U.: Observations of respiratory $\mathrm{CO}_{2}$ and $\mathrm{O}_{2}$ in infants with periodic breathing: In: Intensivpflege bei Neugeborenen-Neonatal Intensive Care, p. 18 (Georg Thieme Verlag, Stuttgart, 1971).

II. Fenner, A., AND Schalk, U.: Influence of ambient $\mathrm{O}_{2}$ on periodic breathing of premature infants. Amer. Soc. Pediat. Res., 260 (1971).

12. Fenner, A., Schalk, U., Hoentcke, H., Wendenburg, A., AND RoEHLING, T.: Observations and studies of periodic breathing in premature and full term infants. Proceedings of the Third European Congress of Perinatal Medicine, Lausanne, Switzerland, 1972 (in press).

13. Graham, B. D., Reardon, H. S., Wilson, J. L., Asao, M. U., AND Baumann, M. L.: Physiologic and chemical response of premature infants to oxygen-enriched atmosphere. Pediatrics, $6: 55(1950)$.

14. HOWARD, P. J., AND BAUER, A. R.: Irregularities of breathing in the newborn period. Amer. J. Dis. Childhood, 77: 592 (1949).

15. Joppich, G., and Schulte, F. J.: Neurologie des Neugeborenen. (Springer-Verlag, New York, 1968).

16. Peiper, A., And Cammann, O.: Kohlensäure bei den Atemstörungen der Neugeborenen und Frühgeborenen. Mschr. Kinderheilk., 53: 323 (1932).

17. Reinstorfe, D., AND FENNER, A.: Ventilatory response to hyperoxia in premature and newborn infants during the first three days of life. Respir. Physiol., 15: 159 (1972).

18. Wilson, J. L., Long, S. B., AND Howard, P.: Respiration of premature infants: response to variations of oxygen and to increased carbon dioxide in inspired air. Amer. J. Dis. Childhood, 63: 1080 (1942).

19. Air Shields apnea monitor, Heinen G.m.b.H., Bonn, Germany.

20. URAS 4, Hartmann and Braun, Frankfurt, Germany.

21. DC 8, Electronics for Medicine, Inc., White Plains, N. Y.

22. Draeger Company, Lübeck, Germany.

23. D2 S, Beckman Instruments, Inc., Fullerton, Calif.

24. This research was supported by Deutsche Forschungsgemeinschaft, grant no. Fe 95/1/3.

25. Requests for reprints should be addressed to: Axel FenNer, Kinderklinik der Medizinischen Akademie, D-24 Lübeck, Germany.

26. Accepted for publication December 11, 1972. 